\title{
The crack growth resistance of thin steel sheets under eccentric tension
}

\author{
L AMBRIŠKO*®i] and L PEŠEK \\ Technical University of Košice, Letná 9, 04200 Košice, Slovak Republic \\ e-mail: lubomir.ambrisko@tuke.sk
}

MS received 1 August 2016; revised 13 July 2017; accepted 31 July 2017; published online 10 March 2018

\begin{abstract}
The stable crack growth in thin steel sheets is the topic of this paper. The crack opening was observed using a videoextensometry system, allowing the crack extension determination. $\mathrm{J}_{\mathrm{R}}$-curve and $\delta_{\mathrm{R}}$-curve were established from obtained data. The ductile tearing properties of different thin sheets of steel were determined, including the impact of the specimen orientation, from test performed on compact tension specimens loaded under two conditions. The effect of the material, the rolling direction, and loading rate on the crack growth resistance of thin steel sheets was analyzed. In addition to the crack growth resistance, $J$-integral values for crack initiation were also estimated. The relation between $J_{i}$ and $J_{0.2}$ was assessed using the basic mathematical and statistical methods. This relation was described by a linear regression model.
\end{abstract}

Keywords. Cold-formed steel; thin sheet; stable crack growth; R-curve; videoextensometry.

\section{Introduction}

Evaluation of the stable crack growth is reworked enough for thicker sheets, but not for steel sheets $(1-2 \mathrm{~mm})$ used for the automotive body. These thin sheets must have equally high resistance toward potential crack growth initiated by crash and so guarantee the safety. The eccentric tension is commonly used for the stable crack growth testing. The load passes by eccentric tension at a certain distance from the crack root. The bending torque creates and it causes a maximum tensile load at the root [1]. The crack growth resistance curve (R-curve) is a suitable method to evaluate the initial stage of stable crack growth [2]. It characterizes the crack growth resistance of a ductile material. Used types of R-curves are:

- $\mathrm{J}_{\mathrm{R}}$-curve (dependency of $J$ on $\Delta a$ ), where $J$ is the value of the $J$-integral corresponding to the stable crack extension $\Delta a$ [3], $J$-integral represents the external load and characterizes the stress state in the vicinity of the crack root, $\Delta a$ is the displacement of the crack due to external load,

- $\delta_{\mathrm{R}}$-curve (dependency of $C T O D$ on $\triangle a$ ), where $C T O D$ is a crack tip opening displacement corresponding to the stable crack extension $\Delta a$ [4].

The $\mathrm{J}_{\mathrm{R}}$-curve is indicative of the materials toughness. As with $J$, several $C T O D$ parameters are defined to describe

\footnotetext{
*For correspondence
}

the various stages and events during ductile and brittle fracture [5].

The stretch zone (SZ) formation prevents the stable crack growth and it is caused by the crack tip blunting. The stretch zone size can be correlated with CTOD, so the stretch zone dimensions can be its measure [6]. The relationship between the critical CTOD for ductile crack initiation $\delta_{i}$ and the stretch zone width $w_{S Z}$ [7] takes the general form of

$$
\delta_{i}=\delta_{0}+\alpha \cdot w_{S Z},
$$

where $\delta_{0}$ is the $C T O D$ at which stretch zones appear on fracture surfaces and is usually considered to be zero. The $\alpha$ is a parameter that depends on the geometry of the blunted crack tip, the definition of $C T O D$ and the method for $w_{S Z}$ measurement. The experimental obtained values of $\alpha$ vary from 1 to 20 [7]. The stretch zones of thin steel sheets were established in work [8]. Between $w_{S Z}$ and the stretch zone height $a_{S Z}$ and also between $w_{S Z}$ and CTOD were determined relation:

$$
\begin{gathered}
w_{S Z}=0.171 a_{S Z}-0.0156, \\
w_{S Z}=0.0855 C T O D-0.0156 .
\end{gathered}
$$

Direct relationship exists between the $w_{S Z}$ and CTOD [9], which also confirms determined linear relation (3) for thin steel sheets. The $\delta_{0}$ is usually considered to be zero and so (3) will change:

$$
w_{S Z}=0.0785 C T O D \text {. }
$$


This new determined relation (4) can be transcribed:

$$
C T O D=12.7 w_{S Z}
$$

and for automotive thin steel sheets the value of the parameter $\alpha$ is 12.7 .

In this work the crack growth resistance of three grades of zinc-coated automotive steel sheets (IF - deep drawing interstitial free steel, DP - dual-phase steel, and microalloyed steel) was determined.

The IF steels are used for the production of extra deep drawing hot dip galvanized sheets for demanding automotive stampings [10]. With respect to the desired properties it is necessary to the greatest extent possible, to attach the already low concentrations of dissolved interstitial compounds to stable compounds of carbide formers and nitride formers [11]. The IF steels have interstitial C and $\mathrm{N}$ atoms untied to stable forms, and therefore not require additional aging and may be processed at a high heating rate and movement of the band, which are necessary for galvanizing or continuous annealing [10]. These steels were developed to achieve extremely high levels of deep drawing. This property is preferred at the expense of strength values, which normally degrades the ability of deep drawing [12].

DP steels are characterized by containing about 5-30\% of martensite in the ferritic matrix [13], and have a low tendency to aging, high strength, and good plastic properties, but low yield strength [11]. Initially, DP steels were developed for the needs of the automotive industry, due to their increased plastic properties like low alloy steels of equivalent strength [14]. A disadvantage is the relatively low coefficient of normal anisotropy [15]. In terms of technological production, low carbon dual-phase steels with ferrite-martensite microstructure are obtained by controlled rolling and cooling or intercritical annealing [16]. DP steels are required in particular by producers of car wheels [17]. Their use is still expanding because of their high strain hardening exponent and more uniform deformation. They are used for production buffers, the chassis components, and so on [18].
The microalloyed steels usually have a ferrite-pearlite structure, and they are a fine grain steels with small quantities of one element or combinations of elements of $\mathrm{Al}$ (min. $0.015 \%), \mathrm{Ti}(\max .0 .1 \%), \mathrm{Nb}(\max .0 .04 \%)$ and $\mathrm{V}$ (max. $0.15 \%$ ), in aggregate micro-alloying content is below $0.15 \%$ [19]. They are used for dynamic stressed parts requiring excellent strength and fatigue characteristics while keeping an excellent bendability and draw ability at mild to moderate degrees of drawing. From the physicalmetallurgical point of view uniform fine-grained structure, good steel purity, and precise control of the level of precipitation strengthening is required. The advantage of these steels is that in addition to maintaining good deep drawing level they have low coefficients of normal anisotropy and are suitable for difficult shape moldings with great resistance to indentation [15].

This work aimed to analyze the effect of the material, the rolling direction, and loading rate on the crack growth resistance of thin steel sheets.

\section{Material and methods}

Three grades of zinc-coated thin steel sheets (figure 1) were used for the investigations:

- deep drawing interstitial free steel XSG with ferrite microstructure $(\mathrm{C}=0.0013 \%)$,

- microalloyed steel HR 45 with ferrite-pearlite microstructure $(\mathrm{C}=0.16 \%)$,

- dual-phase (DP) steel with ferrite-martensite microstructure $(\mathrm{C}=0.072 \%)$.

Thickness $B$ and mechanical properties by loading rate $0.0217 \mathrm{~mm} / \mathrm{s} \quad\left(0.2 \%\right.$ offset yield strength $R_{p 0.2}$, yield strength $R_{e}$, tensile strength $R_{m}$, and elongation $A_{80}$ ) of the investigated steel sheets are shown in table 1 .

The stable crack growth testing was performed using compact tension (CT) specimens $(W=50 \mathrm{~mm})$ with an electro-spark produced notch with tip radius $0.1 \mathrm{~mm}$, but CT specimen usually has notch that ends with a fatigue precrack. No important differences in the stable crack
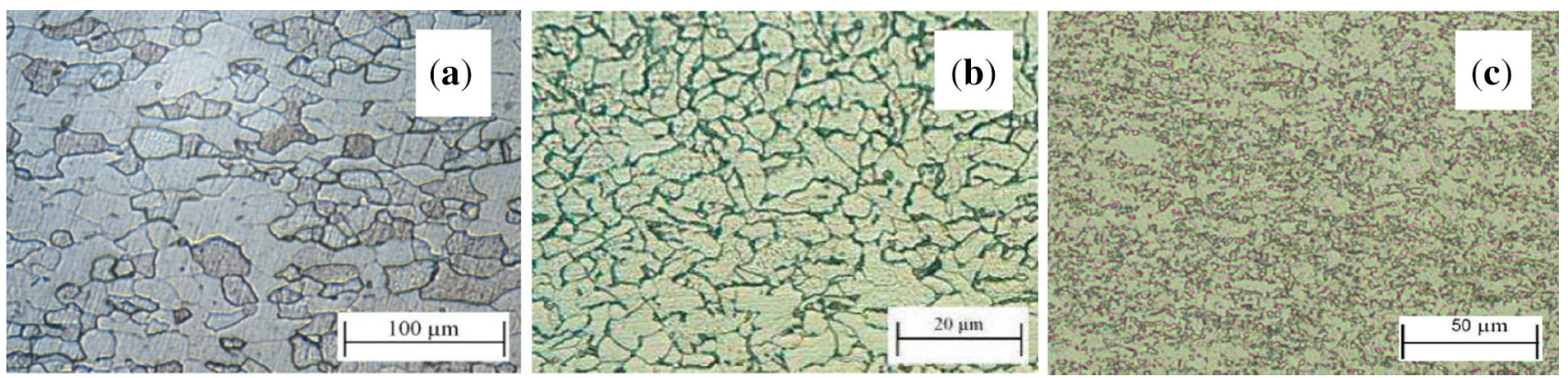

Figure 1. Microstructure of the investigated steels: (a) XSG, (b) HR 45, and (c) DP. 
Table 1. Mechanical properties of the investigated steels.

\begin{tabular}{lccccc}
\hline Steel & $B(\mathrm{~mm})$ & Direction & $R_{p 0.2}(\mathrm{MPa})$ & $R_{m}(\mathrm{MPa})$ & $A_{80}(\%)$ \\
\hline XSG & 1.95 & $\mathrm{~T}$ & 171 & 287 & 48.2 \\
& & $\mathrm{~L}$ & 182 & 285 & 46.1 \\
HR 45 & 1.80 & $\mathrm{~T}$ & $370^{\mathrm{a}}$ & 455 & 27.7 \\
& & $\mathrm{~L}$ & $350^{\mathrm{a}}$ & 443 & 26.3 \\
DP & \multirow{2}{*}{1.60} & $\mathrm{~T}$ & 388 & 581 & 26.1 \\
& & $\mathrm{~L}$ & 372 & 570 & 26.2 \\
\hline
\end{tabular}

${ }^{\mathrm{a}} R_{e}$ - upper yield strength, yield strength for $0.2 \%$ deformation $\left(R_{\mathrm{p} 0.2}\right)$ is determined in case of missing $R_{\mathrm{e}}$.

$\mathrm{L}$, loading in parallel direction to rolling direction; T, loading in perpendicular direction to the rolling direction.

growth resistance of both fatigue precracked and electrospark notched specimens of investigated steels were observed in [20].

Since CT specimens of thin sheets are prone to buckling [21-24], specimens with anti-buckling plates (figure 2) were loaded $(0.0217$ and $2.17 \mathrm{~mm} / \mathrm{s})$ by eccentric tension on a tensile testing machine Heckert Vebthüringer Industriewerk Rauenstein type FP 100/1 (loads up to $100 \mathrm{kN}$ ), whereby the deformation in the notch area was recorded by a non-contact displacement measurement - a videoextensometry technique $[25,26]$.

The crack mouth opening displacement (CMOD) was determined by continual recording of the co-ordinates of centre of gravity of the dots applied properly in the notch area by appropriate software. The crack growth $\Delta a$ was evaluated using a special program based on MATLAB software from recorded images in both directions, perpendicular (LT) and parallel to the rolling direction (TL). The $C M O D$ values have been transformed to $C T O D$ [27] values using the plastic hinge model [28]:

$$
C T O D=\frac{[n(W-a)+\Delta a] V}{[n(W-a)+a+z]}
$$

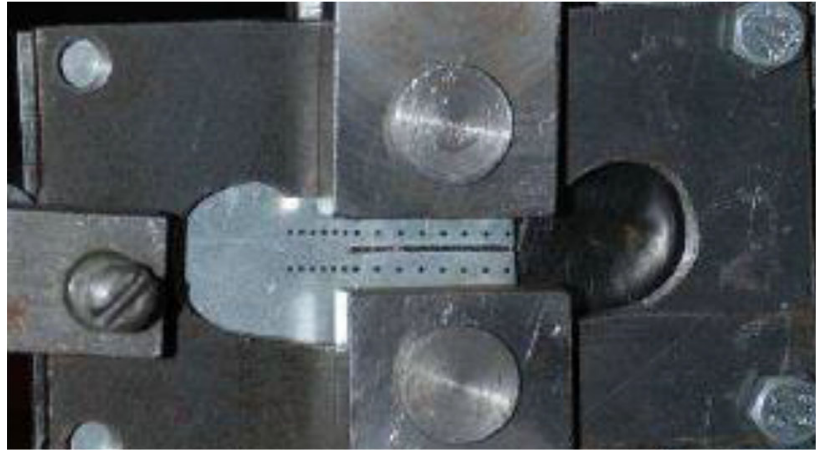

Figure 2. CT specimen with anti-buckling plates.

where $n, W, a, \Delta a, V$, and $z$ denote $n=0.4(1+\beta)$; $\beta=f\left(\frac{a}{W-a}\right)$, width of specimen, crack length, crack growth, notch opening and distance of measurement point from the load-line (if displacement is measured along the load-line, $z=0$ ), respectively.

The $J$-integral values were determined accordingly [28]:

$$
J=\frac{\eta A}{B\left(W-a_{0}\right)}
$$

where $\eta=2+0.522\left(1-a_{0} / W\right), A$ is the area under the load-displacement curve, $B$ is thickness of specimen, and $a_{0}$ is the initial crack length.

R-curves were determined from the obtained data. $\mathrm{R}$-curve characterizes the crack growth resistance of a ductile material. The relationship between the applied value of $J$-integral and amount of the stable crack extension $(\Delta a)$ is known as the $\mathrm{J}_{\mathrm{R}}$-curve. The $J$-integral and $\mathrm{J}_{\mathrm{R}}$-curve are the most important material parameters in elastic-plastic fracture mechanics [29]. The crack tip opening displacement $C T O D(\delta)$ is an alternative to the $J$-integral for representing the crack growth resistance of materials under (a)

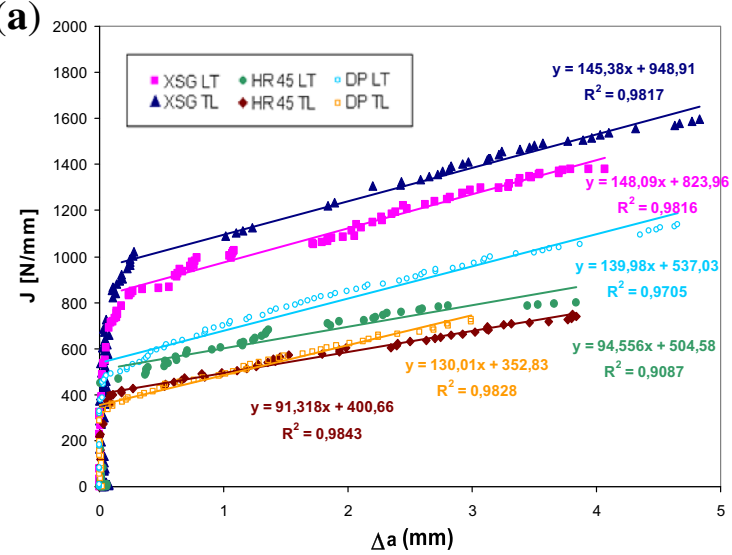

(b)

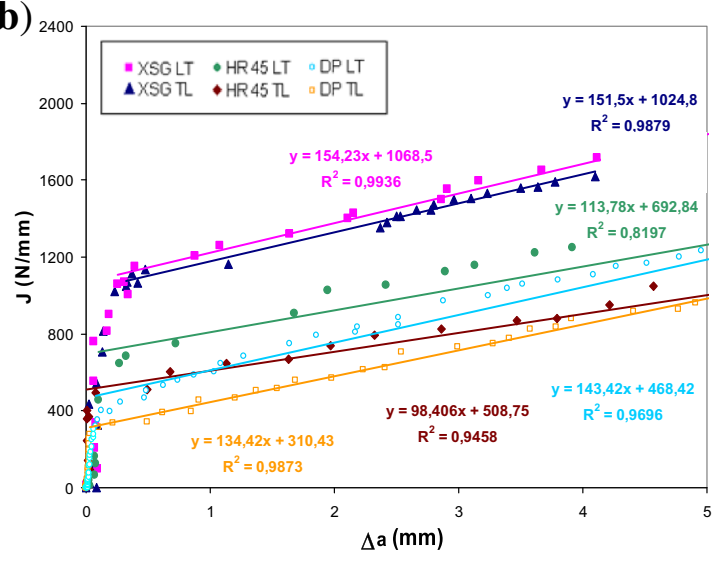

Figure 3. $\mathrm{J}_{\mathrm{R}}$-curve of the investigated steels: (a) loading rate $0.0217 \mathrm{~mm} / \mathrm{s}$ and (b) loading rate $2.17 \mathrm{~mm} / \mathrm{s}$. 

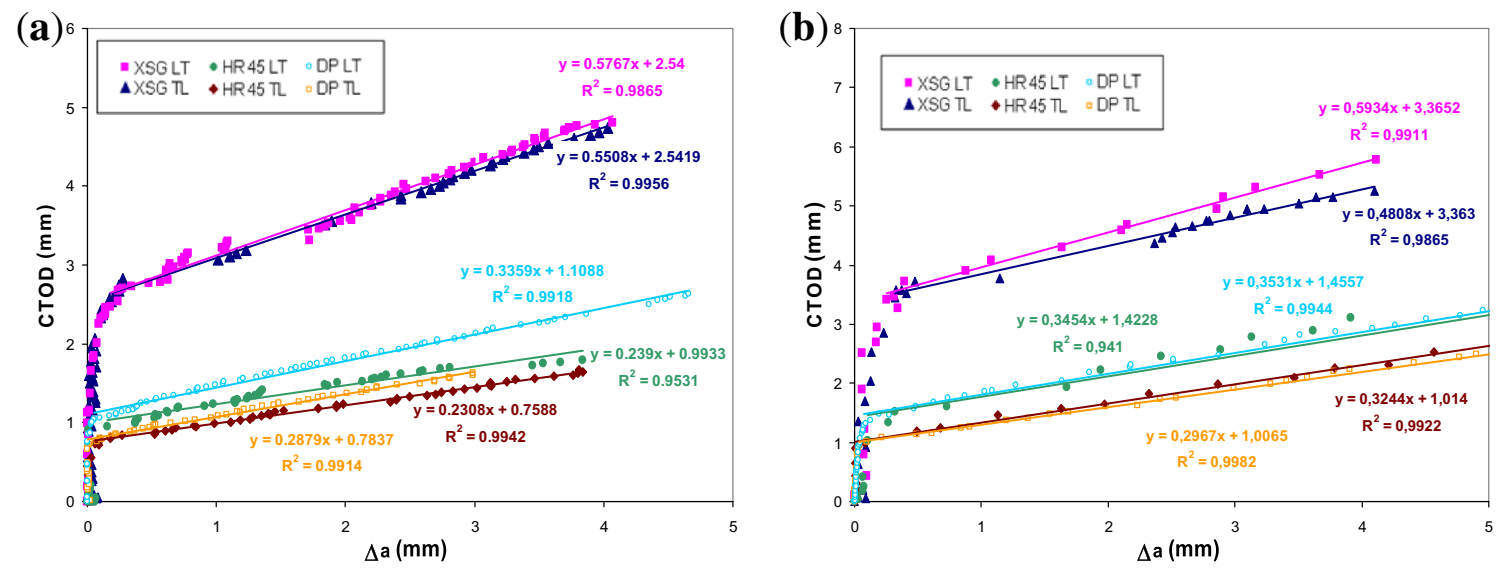

Figure 4. $\delta_{\mathrm{R}}$-curve of the investigated steels: (a) loading rate $0.0217 \mathrm{~mm} / \mathrm{s}$ and (b) loading rate $2.17 \mathrm{~mm} / \mathrm{s}$.

Table 2. The crack growth resistance characteristics of the investigated steels.

\begin{tabular}{|c|c|c|c|c|c|c|}
\hline \multirow[b]{2}{*}{ Steel } & \multicolumn{3}{|c|}{$0.0217 \mathrm{~mm} / \mathrm{s}$} & \multicolumn{3}{|c|}{$2.17 \mathrm{~mm} / \mathrm{s}$} \\
\hline & $\begin{array}{c}d J / d a \\
(\mathrm{~N} / \\
\left.\mathrm{mm}^{2}\right)\end{array}$ & $T(-)$ & $\begin{array}{c}d C T O D / \\
d a(-)\end{array}$ & $\begin{array}{c}d J / d a \\
(\mathrm{~N} / \\
\left.\mathrm{mm}^{2}\right)\end{array}$ & $T(-)$ & $\begin{array}{c}d C T O D / \\
d a(-)\end{array}$ \\
\hline XSG TL & 145 & 528 & 0.551 & 152 & 550 & 0.481 \\
\hline XSG LT & 148 & 538 & 0.577 & 154 & 560 & 0.593 \\
\hline HR $45 \mathrm{TL}$ & 91.3 & 100 & 0.231 & 98.4 & 108 & 0.324 \\
\hline HR 45 LT & 94.6 & 104 & 0.239 & 114 & 125 & 0.345 \\
\hline DP TL & 130 & 124 & 0.288 & 134 & 129 & 0.297 \\
\hline DP LT & 140 & 134 & 0.336 & 143 & 137 & 0.353 \\
\hline
\end{tabular}

LT, crack growth in perpendicular direction to the rolling direction; TL, crack growth in parallel direction to the rolling direction

elastic-plastic condition. CTOD resistance curve, $\delta_{\mathrm{R}}$-curve, was established for each steel too.

The tearing modulus $T$ is a measure of the resistance of the material to tearing and an indication of the stability of the crack growth. The tearing modulus represents a dimensionless form of the $\mathrm{J}_{\mathrm{R}}$-curve slope and is expressed by the following equation $[30,31]$ :

$$
T=\frac{d J}{d a} \frac{E}{R_{e m}^{2}} ; R_{e m}=\frac{R_{e}+R_{m}}{2}
$$

where $d J / d a$ is the $\mathbf{J}_{\mathrm{R}^{-c u r v e}}$ slope, $E$ is Young's modulus, $R_{e}$ is yield strength, and $R_{m}$ is tensile strength.

\section{Results and discussion}

Monitoring the crack growth by a camera is not uncommon $[32,33]$ and crack growth tests are mostly based on the periodical extraction of crack length information [34]. Determined R-curves are presented in figures 3 and 4 in terms of both $J$-integral and CTOD under two loading conditions. Between $C T O D$ and $J$-integral exists a linear relationship [35]. The full $\mathrm{J}_{\mathrm{R}}$-curve is a material property [5]. The $\mathrm{J}_{\mathrm{R}}$-curve for the stable crack growth is commonly used, although it is accepted that the $J_{R}$-curve may depend on the geometry of the specimen or of the component [36]. The range of validity (i.e., the geometry independence) is obviously much larger for $\delta_{R}$-curve than that for $J_{R}$-curve [37].

Maximum $C T O D$ as well as $J$-integral values were obtained for XSG steel, whereby comparing the loading rates higher values of $J$-integral and CTOD were determined by the loading rate of $2.17 \mathrm{~mm} / \mathrm{s}$.

The R-curve slope characterizes the crack growth resistance and is shown in table 2. The crack growth resistance characteristics $(d C T O D / d a, d J / d a$ and $T)$ of steel XSG (table 2) reach the highest values, lowest values were determined for steel HR 45 . The crack growth resistance characteristics of the investigated steels depend on the orientation of the crack to the rolling direction as well as on the loading rate.

The crack growth resistance characteristics were analysed in dependence of tensile properties (yield stress $R_{p 0.2}$ or $R_{e}$, tensile strength $R_{m}$ and elongation $A_{80}$ ). Dependency of both $T$ and $d C T O D / d a$ on mechanical properties is shown in figure 5 . The dependence for $d J / d a$ is identical as for $T$.

We found that $T$ and $d C T O D / d a$ of investigated steels increase with increasing ductility.

$T$ and $d C T O D / d a$ of higher strength steels (HR 45 and DP) increase with increasing both yield stress and tensile strength. XSG steel with lowest both yield stress and tensile strength has $2-3 \times$ higher values of $T$ and $d C T O D / d a$ comparing with DP and HR 45.

The crack growth resistance characteristics by the crack growth in the direction perpendicular to the rolling direction (LT) are higher as compared to that in the rolling direction (TL) (table 2). The inclusions are responsible for initiating and developing of failure, and they affect failure 

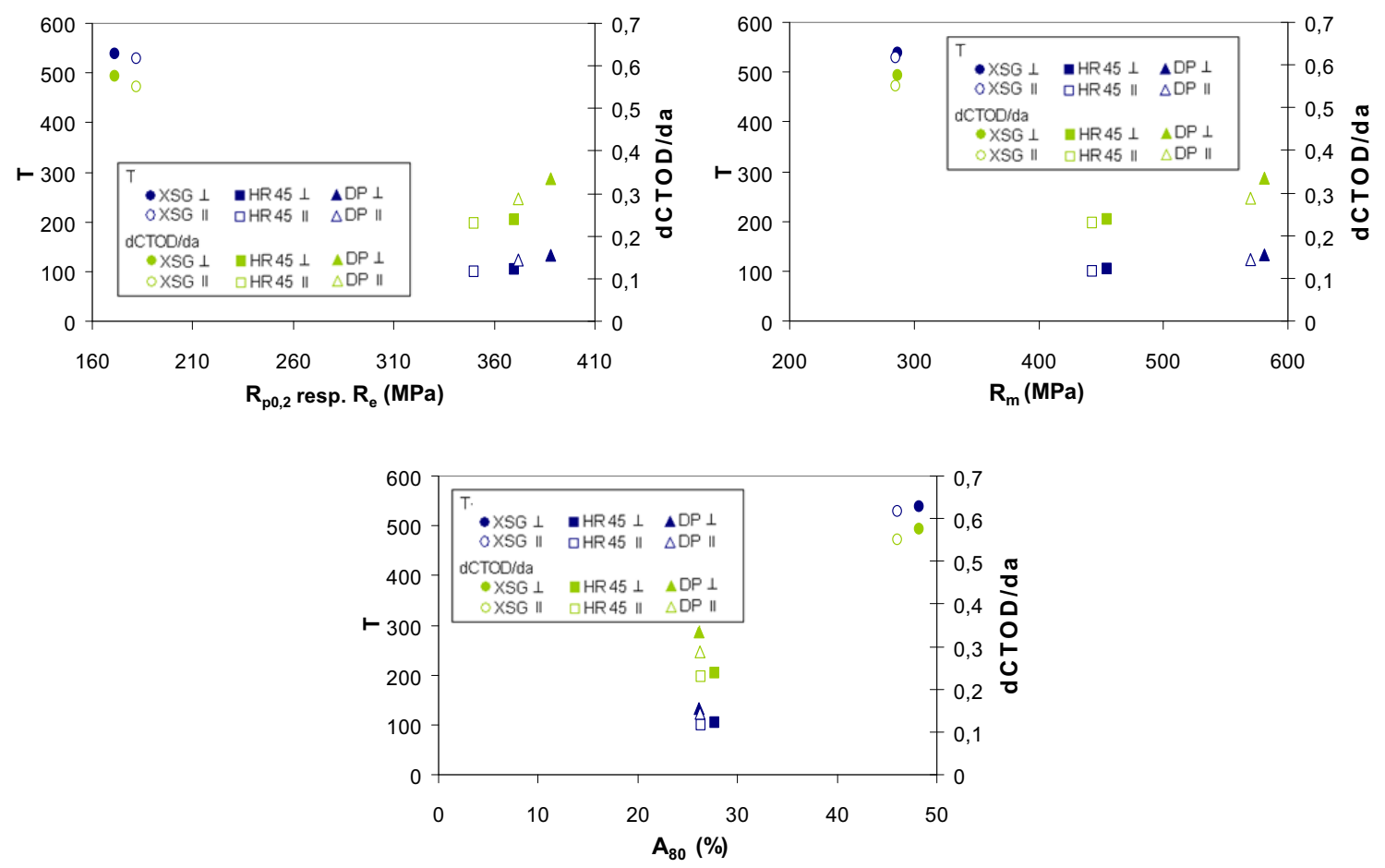

Figure 5. Relation between both, $T, d C T O D / d a$ and tensile properties.
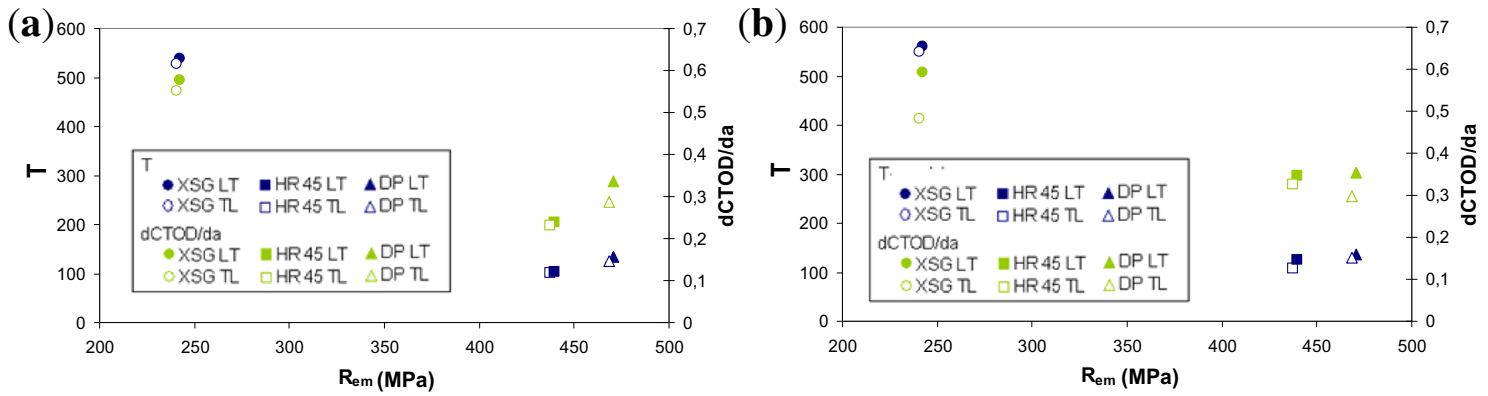

Figure 6. The crack growth resistance characteristics of the investigated steels: (a) loading rate $0.0217 \mathrm{~mm} / \mathrm{s}$ and (b) loading rate $2.17 \mathrm{~mm} / \mathrm{s}$.

in different planes differently [38]. Inclusions (sulphides) direct by rolling in rolling direction and this result in band microstructure, which was supported on steels DP and HR 45 by SEM.

The crack growth resistance characteristics ( $T$ and $d C T O D / d a$ ) of the investigated steels for various loading rates are presented in figure 6.

The crack growth resistance characteristics of steel HR 45 by loading rate $0.0217 \mathrm{~mm} / \mathrm{s}$ in direction perpendicular to the rolling direction (LT) are slightly higher than in the rolling direction (TL). Differences of individual characteristics for other steels are diverse. Slope $d C T O D / d a$ of XSG steel for LT direction is higher by $23 \%$ comparing with the TL direction by loading rate $2.17 \mathrm{~mm} / \mathrm{s}$, this is the maximum difference found. Slope $d J / d a$ and $T$ of XSG steel investigated loading rates for LT direction are slightly higher than for TL direction. Slope $d C T O D / d a$ of XSG and DP steels for LT direction reaches maximum difference comparing with TL direction for both loading rates.

Influence of loading rate on the crack growth resistance is not negligible. By the loading rate of $2.17 \mathrm{~mm} / \mathrm{s}$ characteristics $d C T O D / d a, d J / d a$ and $T$ of investigated steels reach higher values as by loading rate of $0.0217 \mathrm{~mm} / \mathrm{s}$ except the slope $d C T O D / d a$ of XSG steel for TL direction. Slope $d J / d a$ and $T$ of steels reach the same differences by comparing both loading rates. The crack growth resistance characteristics of steel DP for TL direction by loading rate $2.17 \mathrm{~mm} / \mathrm{s}$ are slightly higher than by loading rate $0.0217 \mathrm{~mm} / \mathrm{s}$. The differences for individual characteristics 


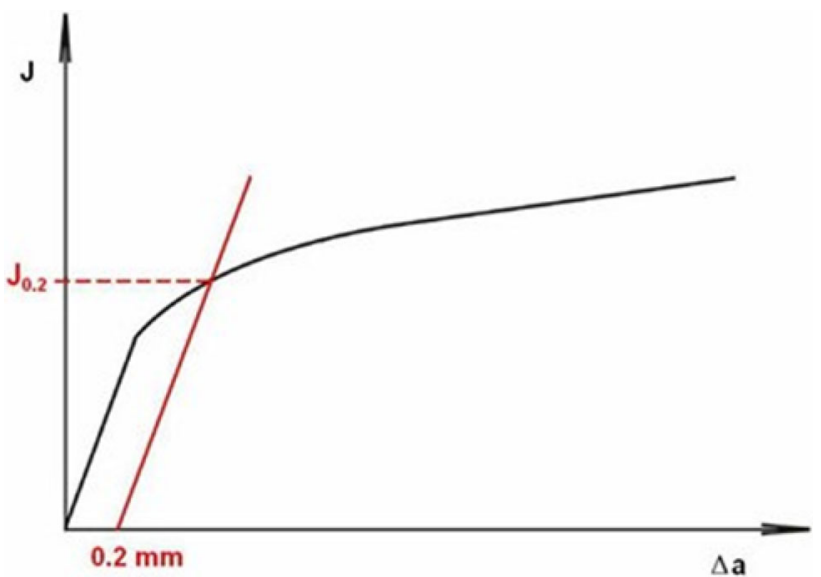

Figure 7. Method of determining $J_{0.2}$ values.

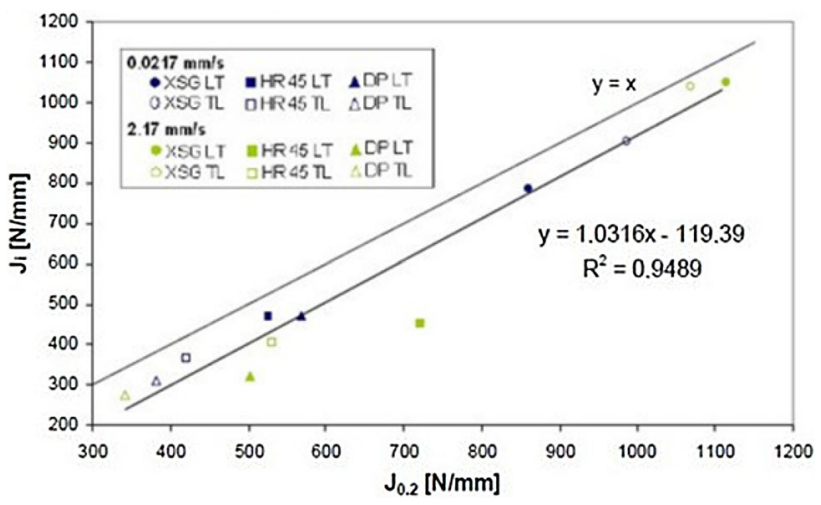

Figure 8. Relation between $J_{i}$ and $J_{0.2}$.

of investigated steels are diverse in other cases. Slope $d C T O D / d a$ of steel HR 45 is larger by the loading rate of $2.17 \mathrm{~mm} / \mathrm{s}$ for both directions. Characteristics of HR 45 steel for LT direction by loading rate $2.17 \mathrm{~mm} / \mathrm{s}$ reach maximum differences by comparing with the loading rate $0.0217 \mathrm{~mm} / \mathrm{s}$.

In addition to the crack growth resistance characteristics were determined $J$-integral values for crack initiation $-J_{0.2}$ and $J_{i}$. The $J_{0.2}$, conventional crack initiation for $0.2 \mathrm{~mm}$ crack propagation [38], was also obtained (figure 7). The real state of crack initiation by experiments was impossible to determine; therefore, the $J_{i}$ was determined for observable crack initiation at recorded images. $J_{0.2}$ for investigated steels reaches higher values than $J_{i}$, because the crack extension for $J_{i}$ is below the $0.2 \mathrm{~mm}$. It was determined a relation between $J_{0.2}$ and $J_{i}$ (figure 8 ). Both $J_{0.2}$ and $J_{i}$ for applied loadings rates are higher in case of the crack growth in direction perpendicular to the rolling direction (LT) as by the crack growth in the rolling direction (TL) with an exception of XSG steel by rate $0.0217 \mathrm{~mm} / \mathrm{s}$. Maximum $J_{0.2}$ as well as $J_{i}$ values were determined for XSG steel and minimum for DP steel.

The relation between $J_{i}$ and $J_{0.2}$ is assessed using the basic mathematical and statistical methods. Estimation of coefficients of the researched regression model is made using the regression analysis. This relation can be described by a linear regression model $\left(R^{2}=0.949\right)$ :

$$
J_{i}=1.032 J_{0.2}-119.39 .
$$

\section{Conclusions}

As with $\mathrm{J}_{\mathrm{R}}$-curve, $\delta_{\mathrm{R}}$-curve can describe the various stages and events during the stable crack growth. The crack growth resistance characteristics (both R-curve slopes $d C T O D / d a$, $d J / d a$, and tearing modulus $T$ ) reach the maximum values for XSG (IF) steel. Minimum values were determined for HR 45 (ferrite-pearlite) steel. The XSG steel has the highest crack growth resistance. Maximum differences between investigated steels were determined in tearing modulus expression.

Tearing modulus and both R-curve slopes of investigated steels increase with increasing ductility. Crack growth resistance characteristics of higher strength steels (HR 45 and DP) increase with increasing both yield stress and tensile strength.

Crack growth direction significantly affects the crack growth resistance. The most sensitive steel on the crack growth direction is DP steel. The crack growth resistance is higher for crack growth perpendicular to the rolling direction by $1.8-23.3 \%$ in dependence of steel grade and loading rate.

Loading rate affects the crack growth resistance. The crack growth resistance characteristics of investigated steel by loading rate $2.17 \mathrm{~mm} / \mathrm{s}$ are larger by $2.4-44.4 \%$ in dependence of the steel grade and the crack growth direction. The most sensitive steel on the loading rate is HR 45 steel.

\section{List of symbols}

A area under the load-displacement curve

$A_{80} \quad$ elongation (initial length $80 \mathrm{~mm}$ )

$a \quad$ crack length

$a_{0} \quad$ initial crack length

$a_{S Z} \quad$ stretch zone height

$\Delta a \quad$ crack propagation

$\alpha \quad$ parameter, values vary from 1 to 20

$B \quad$ thickness

CMOD crack mouth opening displacement

CT compact tension

CTOD crack tip opening displacement

( $\delta)$ 


\begin{tabular}{|c|c|}
\hline$\delta_{0}$ & $\begin{array}{l}C T O D \text { at which stretch zones appear on } \\
\text { fracture surfaces }\end{array}$ \\
\hline$\delta_{i}$ & critical $C T O D$ for ductile crack initiation \\
\hline$\delta_{\mathrm{R}}$-curve & $C T O D$ resistance curve \\
\hline $\begin{array}{l}d C T O D / \\
d a\end{array}$ & slope of $\delta_{\mathrm{R}}$-curve \\
\hline DP & dual-phase steel \\
\hline$d J / d a$ & slope of $\mathrm{J}_{\mathrm{R}}$-curve \\
\hline$E$ & Young's modulus \\
\hline HR 45 & microalloyed steel \\
\hline IF & interstitial free steel \\
\hline$J$-integral & $\begin{array}{l}\text { line integral (path-independent) around the } \\
\text { crack tip }\end{array}$ \\
\hline$J_{i}$ & $\begin{array}{l}\text { value of } J \text {-integral for observable crack } \\
\text { initiation }\end{array}$ \\
\hline $\mathrm{J}_{\mathrm{R}}$-curve & $J$-integral resistance curve \\
\hline$J_{0.2}$ & $\begin{array}{l}\text { value of } J \text {-integral of conventional crack } \\
\text { initiation for } 0.2 \mathrm{~mm} \text { crack propagation }\end{array}$ \\
\hline$R_{e}$ & yield strength \\
\hline$R_{m}$ & tensile strength \\
\hline$R_{p 0.2}$ & $0.2 \%$ offset yield strength \\
\hline SEM & scanning electron microscopy \\
\hline SZ & stretch zone \\
\hline$T$ & tearing modulus \\
\hline$V$ & notch opening \\
\hline$W$ & width \\
\hline$w_{S Z}$ & stretch zone width \\
\hline$z$ & $\begin{array}{l}\text { distance of measurement point from the load- } \\
\text { line }\end{array}$ \\
\hline
\end{tabular}

\section{References}

[1] Veles P 1989 Mechanical properties and material testing. Bratislava, ALFA (in Slovak)

[2] Pešek L, Oravec K and Boháč I 1994 Resistance to stable crack growth in welded joints of microalloyed strip steel. In: Zváranie 94, 11.-12.5.1994, Bratislava, Slovakia (in Slovak)

[3] Pešek L and Boháč I 1994 Resistance to stable crack growth in welded joints rated by a one-sample method. In: Materiál $v$ inžinierskej praxi 94, 16.-18.5.1994, Herl' any, Slovakia (in Slovak)

[4] Pešek L and Oravec K 1994 Patterns of stable crack growth in microalloyed steel strips. Ocel'. Plechy 21: 19-25 (in Slovak)

[5] Saxena A 1998 Nonlinear fracture mechanics for engineers. Boca Raton, CRC Press

[6] Bassim M N 1995 Use of the stretch zone for the characterization of ductile fracture. J. Mater. Proc. Technol. 54: 109-113

[7] Barnhurst R J and Gruzleski J E 1985 Fracture toughness and its development in high purity cast carbon and low alloy steels. Metall. Trans. A. 16(4): 613-622

[8] Ambriško L' and Pešek L 2014 The stretch zone of automotive steel sheets. Sadhana 39: 525-530
[9] Mao X 1991 Influence of specimen size on I-III mixed mode fracture, fracture toughness $\mathrm{J}_{\mathrm{IC}}$ and plastic dissipation with crack growth $\mathrm{dW}_{\mathrm{p}} / \mathrm{da}$. Eng. Fract. Mech. 38: 241-254

[10] Billy J, Slávik P, Mikolaj L', Hala K and Záboj J 1997 Hotdip galvanized sheets produced by VSŽ for automotive industry. In: Sheets for the automotive industry. Stará Lesná, Slovakia (in Slovak)

[11] Bhadeshia H K D H and Honeycombe R W K 2006 Steels: microstructure and properties. Oxford: Elsevier

[12] Billy J, Štefan B, Slávik P, Gašpar V, Mikolaj L' and Záboj J 1994 Specifics of dip galvanized sheet for the purpose of bodywork. Hut. Listy 5: 15-20 (in Slovak)

[13] Hüper T, Endo S, Ishikawa N and Osawa K 1999 Effect of volume fraction of constituent phases on the stress-strain relationship of dual phase steels. ISIJ Int. 39(3): 288-294

[14] Kuzičkin D et al 1988 Structural steels formed and for castings. Bratislava, Alfa (in Slovak)

[15] Štefan B and Šlesár M 1992 Physical-metallurgical concept of modern deep drawing cold rolled steels. Ocel'. Plechy 1-2: 3-10

[16] Cosmo M, Galantucci L M and Tricarico L 1999 Design of process parameters for dual phase steel production with strip rolling using the FEM. J. Mater. Technol. 92-93: 486-493

[17] Juhar L' and Peterčáková A 2005 Production and properties of the new hot rolled ferritic-martensitic steels. Acta Metall. Slovaca 11: 104-108

[18] Skočovský P and Konečná R 1996 New construction materials, selected chapter II. Žilina, University of Žilina (in Slovak)

[19] Porter D A and Easterling K E 1996 Phase transformations in metals and alloys. London: Chapman \& Hall

[20] Ambriško L and Pešek L 2011 Determination the crack growth resistance of automotive steel sheets. Chem. Listy 105(17): 767-768

[21] Sultan A, Pasha R A, Ali M, Khan M Z, Khan M A, Dar N U and Shah M 2013 Numerical simulation and experimental verification of CMOD in SENT specimen: application on FCGR of welded tool steel. Acta Metall. Sinica 26: 92-96

[22] Kulkarni D M, Prakash R, Talan P and Kumar A N 2004 The effect of specimen thickness on the experimental and finite element characterization of CTOD in extra deep drawn steel sheets. Sadhana 29: 365-380

[23] Gullerud A S, Dodds Jr. R H, Hampton R W and Dawicke D S 1999 3D modeling of ductile crack growth in thin sheet metals: computational aspects and validation. Eng. Fract. Mech. 63: 347-374

[24] Shahani A R, Rastegar M, Botshekanan Dehkordi M and Moayeri Kashani H 2010 Experimental and numerical investigation of thickness effect on ductile fracture toughness of steel alloy sheets. Eng. Fract. Mech. 77: 646-659

[25] Ambriško L' and Pešek L 2009 Accuracy of strain measurement using ME 46 videoextensometric system. Acta Metall. Slovaca 15(2): 105-111

[26] Ambriško L, Kandra T and Pešek L 2011 Rating indentation and deformation characteristics laser welds. Chem. Listy 105(14): 150-154

[27] BS 57621979 Methods for crack opening displacement (COD) Testing

[28] ESIS PI-92 1992 Recommendations for determining the fracture resistance of ductile materials 
[29] Zhu X 2009 J-integral resistance curve testing and evaluation. J. Zhejiang Univ.-Sci. A 10(11): 1541-1560

[30] Lampman S R et al 1996 ASM handbook. Fatigue and fracture, vol. 19. Ohio, ASM International

[31] Broek D 1984 Elementary engineering fracture mechanics. The Hague, Martinus Nijhoff Publisher

[32] Kayamori Y, Hillmansen S, Crofton P S J and Smith R A 2007 Ductile crack propagation characteristics in steel thin single edge notched tension specimens. Mater. Sci. Forum 539-543: 2180-2185

[33] Bernstone C and Heyden A 2009 Image analysis for monitoring of crack growth in hydropower concrete structures. Measurement 42: 878-893

[34] Richter-Trummer V, Marques E A, Chaves F J P, Tavares J M R S, da Silva L F M and de Castro P M S T 2011 Analysis of crack growth behavior in a double cantilever beam adhesive fracture test by different digital image processing techniques. Materialwiss. Werkstofftech. 42(5): 452-459

[35] Shih C F 1981 Relationship between crack tip opening displacement for stationary and extending cracks. J. Mech. Phys. Solids. 29: 305-326

[36] Dhar S, Marie S and Chapuliot S 2008 Determination of critical fracture energy, $\mathrm{G}_{\mathrm{fr}}$, from crack tip stretch. Int. J. Pressure Vessels Piping 85: 313-321

[37] Brocks W, Anuschewski P and Scheider I 2010 Ductile tearing resistance of metal sheets. Eng. Failure Anal. 17: 607-616

[38] Wagner D, Moreno J C, Prioul C, Frund J M and Houssin B 2002 Influence of dynamic strain aging on the ductile tearing of C-Mn steels: modelling by a local approach method. $J$. Nucl. Mater. 300: 178-191 